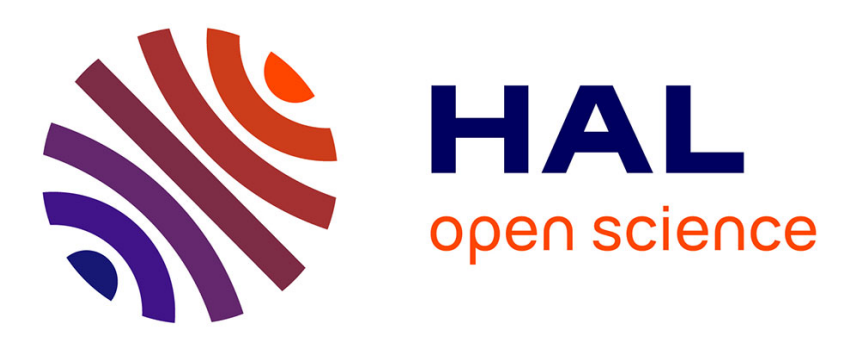

\title{
A study of water releases in ground (GCC) and precipitated (PCC) calcium carbonates
}

G. Renaudin, Anne Bertrand, M. Dubois, S. Gomes, P. Chevalier, A. Labrosse

\section{To cite this version:}

G. Renaudin, Anne Bertrand, M. Dubois, S. Gomes, P. Chevalier, et al.. A study of water releases in ground (GCC) and precipitated (PCC) calcium carbonates. Journal of Physics and Chemistry of Solids, 2009, 69 (7), pp.1603. 10.1016/j.jpcs.2007.12.001 . hal-00522550

\section{HAL Id: hal-00522550 \\ https://hal.science/hal-00522550}

Submitted on 1 Oct 2010

HAL is a multi-disciplinary open access archive for the deposit and dissemination of scientific research documents, whether they are published or not. The documents may come from teaching and research institutions in France or abroad, or from public or private research centers.
L'archive ouverte pluridisciplinaire HAL, est destinée au dépôt et à la diffusion de documents scientifiques de niveau recherche, publiés ou non, émanant des établissements d'enseignement et de recherche français ou étrangers, des laboratoires publics ou privés. 


\section{Author's Accepted Manuscript}

A study of water releases in ground (GCC) and precipitated (PCC) calcium carbonates

G. Renaudin, A. Bertrand, M. Dubois, S. Gomes, P. Chevalier, A. Labrosse

PII: $\quad$ S0022-3697(07)00755-X

DOI: $\quad$ doi:10.1016/j.jpcs.2007.12.001

Reference: $\quad$ PCS 5336

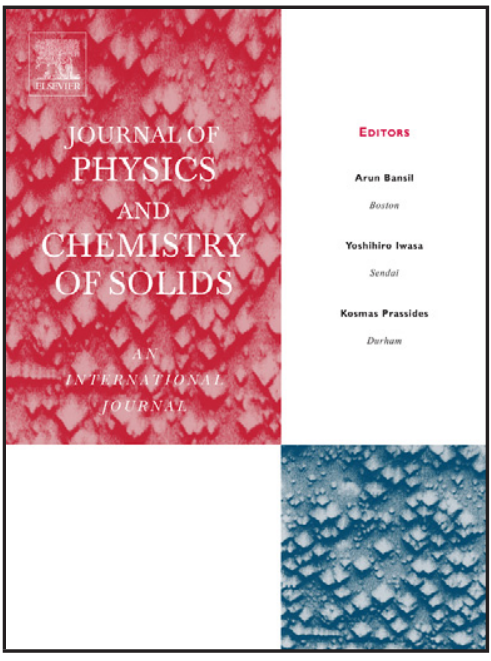

www.elsevier.com/locate/jpcs

To appear in: Journal of Physics and

Chemistry of Solids

Received date: $\quad 2$ May 2007

Revised date: $\quad 6$ November 2007

Accepted date: 3 December 2007

Cite this article as: G. Renaudin, A. Bertrand, M. Dubois, S. Gomes, P. Chevalier and A. Labrosse, A study of water releases in ground (GCC) and precipitated (PCC) calcium carbonates, Journal of Physics and Chemistry of Solids (2007), doi:10.1016/j.jpcs.2007.12.001

This is a PDF file of an unedited manuscript that has been accepted for publication. As a service to our customers we are providing this early version of the manuscript. The manuscript will undergo copyediting, typesetting, and review of the resulting galley proof before it is published in its final citable form. Please note that during the production process errors may be discovered which could affect the content, and all legal disclaimers that apply to the journal pertain. 


\title{
A study of water releases in ground (GCC) and precipitated (PCC) calcium carbonates
}

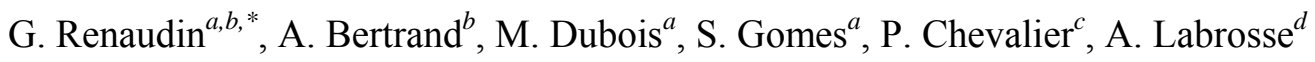 \\ a Laboratoire des Matériaux Inorganiques, UMR 6002, Université Blaise Pascal de \\ Clermont-Ferrand, F-63177 Aubière Cedex, France, ${ }^{b}$ Ecole Nationale Supérieure de Chimie \\ de Clermont-Ferrand, F-63174 Aubière Cedex, France, ${ }^{\mathrm{c}}$ Dow Corning S.A., Surface and \\ Interface Solutions Center, B-7180 Seneffe, Belgium, ${ }^{\mathrm{d}}$ Dow Corning S.A., SEU-Analytical \\ Sciences, B-7180 Seneffe, Belgium.
}

* Corresponding author: guillaume.renaudin@ensccf.fr, tel.: (+33) 47340 7336, fax: (+33) 473407108

\begin{abstract}
Precipitate Calcium Carbonates (PCCs) are important industrial products mainly used as fillers. Because of their regular, synthesized characteristics (e.g. grain shape or grain size distribution) PCCs are distinct from natural Ground Calcium Carbonates (GCCs). A thermal study on GCC samples showed only the presence of surface physisorbed water with a monotonic weight loss up to the carbonate decomposition. In the case of PCC samples, two supplementary water releases were observed. The first one appeared at around $525 \mathrm{~K}$ and the second one at around $725 \mathrm{~K}$. The nature of the water present in two different PCC samples was investigated by thermal analyses (thermogravimetric and Karl Fischer analyses), Rietveld analyses on X-rays powder diffraction, infrared and Raman spectroscopies and solid state ${ }^{1} \mathrm{H}$ MAS NMR. The second water release at about $725 \mathrm{~K}$ was clearly identified as being portlandite dehydration. $\mathrm{Ca}(\mathrm{OH})_{2}$ was present in the PCC in an amorphous state. Its crystallization occurred simultaneously to the first water release at about $525 \mathrm{~K}$. Structural effects observed on calcite during the first water release led to the assignment to structural water molecules inserted in the structure of calcite.
\end{abstract}

\section{Keywords}

Precipitated calcium carbonate (PCC), ground calcium carbonate (GCC), water release, calcite, portlandite, structural water. 


\section{Introduction}

Calcium carbonate is used as fillers for numerous applications, including thermoplastics. Ground Calcium Carbonates (GCC: ground from natural chalk, limestone or marble) are generally used as fillers with an interesting performance/price ratio. However, more expensive Precipitated Calcium Carbonates ( $\mathrm{PCC}$, synthetic $\mathrm{CaCO}_{3}$ ) can be used to fulfil additional needs like processing aid, impact modification and better weatherability [1-3]. PCCs are much more than a filler, namely because of their regular and controlled crystalline shape, ultrafine particle size and narrowness of particle size distribution. PCCs are obtained by reaction of gaseous carbon dioxide with a colloidal suspension of calcium hydroxide and can be decomposed by the two simple following reactions:

$$
\begin{aligned}
& \text { - thermal decomposition of GCC: } \mathrm{CaCO}_{3} \stackrel{\Delta \mathrm{T}, \mathrm{CO}_{2} \uparrow}{\longrightarrow} \mathrm{CaO} \stackrel{+\mathrm{H}_{2} \mathrm{O}}{\longrightarrow} \mathrm{Ca}(\mathrm{OH})_{2} \\
& \text { - controlled precipitation of PCC: } \mathrm{Ca}(\mathrm{OH})_{2}+\mathrm{CO}_{2} \longrightarrow \mathrm{CaCO}_{3}+\mathrm{H}_{2} \mathrm{O}
\end{aligned}
$$

The synthesis process is sufficiently versatile to allow a number of different morphological characteristics to be developed [2-4]. However, calcium carbonates are containing various levels of moisture, which impose careful storage or the use of desiccant additives such as $\mathrm{CaO}$ to preserve the final properties of e.g. thermoplastic films [5]. Indeed, compared to GCC, two additional water releases were observed when heating PCC at around 525 and $725 \mathrm{~K}$. These two water losses were superimposed on the monotonic weight loss observed from room temperature (RT) up to the temperature of decomposition of the carbonate (i.e. about $1025 \mathrm{~K}$ ). The monotonic weight loss was present in both PCC and GCC cases and was assigned to both physisorbed surface water molecules and to the beginning of the decarbonation process. The physisorbed water was correlated to the specific surface area of the samples. The present study, realised in partnership with Specialty Minerals Inc., was aimed at identifying the origin and nature of the two additional kinds of water present in PCCs, that can be considered as the main impurity. Water losses were identified and quantified by several techniques, namely thermogravimetric analysis (TGA) and Karl Fischer analysis (KF), correlated with a previous study by thermal analysis at controlled kinetics coupled together with mass spectroscopy [6]. Powder X-rays diffraction, vibrational spectrometry and solid state ${ }^{1} \mathrm{H}$ MAS NMR were further used to elucidate the origin of these two water losses from PCCs. 


\section{Experimental}

\subsection{Samples and thermal treatments}

Three different samples were investigated in this study. Two commercial PCCs, named PCC1 and PCC-2, were selected because of their different thermal behaviour. Indeed, the PCC-1 weight losses were more pronounced than the ones of sample PCC-2. This study was realised in partnership with Specialty Minerals Inc., the minerals producer of PCC-1 and PCC-2 under the respective trade names Albafil and Calofort U. A third GCC sample (Millicarb from Omya) was used as a reference material exhibiting only a monotonic weight loss before the thermal decomposition of carbonate. Table 1 gives the physical properties of the samples. The characterization made on the PCC-1 and GCC samples agreed with the indication given by the manufacturers. In the case of the PCC-2 the measured specific surface area was accurate but the median grain size and grain size distribution were larger than the given indications. This has to be explained by the grains agglomeration in this sample. Nevertheless the three samples presented quite equivalent physical characteristics. Figure 1 shows the thermal behaviour of these three samples from RT up to $825 \mathrm{~K}$.

Thermal treatments were applied to these three calcium carbonates: 15 hours in a furnace from $325 \mathrm{~K}$ up to $775 \mathrm{~K}$ by steps of $50 \mathrm{~K}$. Eleven samples (as-synthesized, $325 \mathrm{~K}, 375 \mathrm{~K}$, $425 \mathrm{~K}, 475 \mathrm{~K}, 525 \mathrm{~K}, 575 \mathrm{~K}, 625 \mathrm{~K}, 675 \mathrm{~K}, 725 \mathrm{~K}$ and $775 \mathrm{~K}$ ) for each carbonate (PCC-1, PCC-2 and GCC) were prepared for this work. The named as-synthesized samples in the text correspond to commercial as-received samples. Infrared and Raman spectroscopy experiments were also carried out on PCC-1 thermally treated at $500 \mathrm{~K}$ and $550 \mathrm{~K}$. After each thermal treatment, samples were analysed by TGA to check the water content and were then stored in a dry box before being studied by the following different analytical techniques.

\subsection{Thermal analyses}

Thermogravimetric analyses (TGA) have been performed on a Mettler Toledo TGA_SDTA 851e apparatus. About $30 \mathrm{mg}$ of powder were introduced in an alumina crucible. Measurements were realized from $300 \mathrm{~K}$ up to $1275 \mathrm{~K}$ with a heating rate of 5

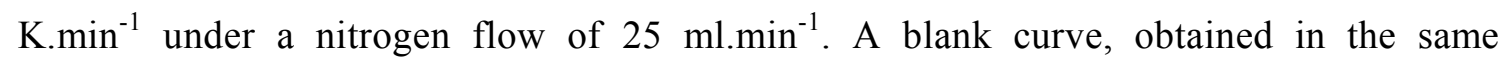
condition with the same empty alumina crucible, was systematically subtracted. Identification of the different weight losses was made by derivative DTA curves. 
Karl Fischer analyses (KF) were performed on a Metrohm coulometric model 756 titrator using a model 768 oven. Experimental KF parameters were optimized to be able to compare TGA and KF data, therefore the experiments were carried out in two steps: one at $393 \mathrm{~K}$ and the second one at $573 \mathrm{~K}$ (see Table 2). Other parameters like sample mass of around $2 \mathrm{~g}$; start and relative drift of around $15 \mathrm{mg} \cdot \mathrm{min}^{-1}$ and nitrogen flow of around 60 ml.min ${ }^{-1}$ were applied.

\subsection{Powder X-rays diffraction (PXRD)}

Powder X-rays diffraction measurements were carried out in order to check the presence of portlandite in PCC. The weight loss measured at $725 \mathrm{~K}$ was close to $0.5 \mathrm{wt} \%$ (weight percent) which corresponds to approximately 2 wt \% of portlandite (Figures 1 and 2). Long time measurements in a quite short two theta range were performed in order to obtain a good statistic counting that allowed to extract low intensity, and possibly broad, peaks from the background. X-rays powder patterns were recorded on a Siemens D5000 diffractometer at room temperature, Bragg-Brentano geometry, $\mathrm{Cu} \mathrm{K}_{\alpha}$ radiation $(\lambda=$ $1.54184 \AA$ ) , two theta range $15-60^{\circ}$, two theta step $0.02^{\circ}, 22$ seconds per step leading to a measuring time of 14 hours for each sample. The chosen two theta range allowed identification of portlandite by its non-overlapped diffraction peaks at $2 \theta=18.06^{\circ}, 34.14^{\circ}$ and $50.88^{\circ}$ [7] and Rietveld refinement of $\mathrm{CaCO}_{3}$ structure (calcite type) by the presence of twelve Bragg peaks [7]. $20 \mathrm{wt} \%$ of pure silicon were added to the sample as internal standard in order to increase the accuracy in two theta position and to determine the instrumental resolution function of the diffractometer. Powder pattern Rietveld refinements were performed with FullProf.2k [8]. The diffraction peak profiles (both instrumental and intrinsic sample) were modelled by using a Thomson-Cox-Hastings pseudo-Voigt function [8] (convolution of Gaussian and Lorentzian components having different full widths at half maximum, FWHM). Lattice parameter of Si (cubic $F d \overline{3} m$ space group) was fixed at $a=5.43088 \AA$. Lattice parameters, oxygen position and microstructure parameters of calcite (rhombohedral $R \overline{3} c$ with $a=4.988 \AA$ and $c=17.061$ $\AA$ [9]) were refined. Lattice and microstructure parameters of portlandite (trigonal $P \overline{3} \mathrm{ml}$ with $a=3.589 \AA$ and $c=4.911 \AA[10]$ ) were refined when observed. Background pattern was modelled with a five coefficients polynomial function. The refined parameters from the X-rays diffraction patterns are gathered in Table 3. The $R p$ and $\chi^{2}$ values indicate the quality of the refinement. The standard deviations (indicated in bracket in Table 3) 
correspond to $3 \sigma$ weighted by $\chi^{2}$ in order to avoid an overestimation on the accuracy of the refined parameters ( $\sigma$ is the standard deviation determined by FullProf.2k).

\subsection{DRIFT spectroscopy}

Diffuse Reflectance Infrared Fourier Transform (DRIFT) spectra were performed on a PerkinElmer System 2000 FTIR spectrometer equipped with a Diffuse Reflectance sphere accessory from SpectraTech. 5\% of sample were intimately mixed and ground with pure $\mathrm{KCl}$ and background spectra were recorded with pure $\mathrm{KCl}$ only. Spectra were obtained at $4 \mathrm{~cm}^{-1}$ spectral resolution from 450 to $5600 \mathrm{~cm}^{-1}, 15$ scans $(165 \mathrm{~s})$, apodization "strong", $\mathrm{KBr}$ beamsplitter, DTGS detector. For peak area measurements, spectra were previously normalized on the calcite peak at $2512 \mathrm{~cm}^{-1}$ at the arbitrary absorbance unit of 0.3 .

\subsection{Raman spectroscopy}

Raman spectra were performed on a Renishaw InVia Reflex Raman Microscope equipped with a CCD detector and a $514 \mathrm{~nm}$ laser source. Powder samples were analysed under a microscope using a x100 magnifying objective and laser power of around $10 \mathrm{~mW}$ at the sample focus. Spectra were typically recorded from 100 to $4000 \mathrm{~cm}^{-1}$ (Notch filter) with a 1800 grooves. $\mathrm{mm}^{-1}$ grating leading to a spectral resolution of around $4 \mathrm{~cm}^{-1} .3$ scans of 15 s were usually recorded. Like for DRIFT, spectra were normalized on a calcite band (1087 $\mathrm{cm}^{-1}$ ) before peak area measurements.

\subsection{Solid state ${ }^{1}$ H MAS NMR}

The solid state ${ }^{1} \mathrm{H}$ MAS NMR spectra were recorded at room temperature with a Bruker MSL300 spectrometer operating at 300.1 MHz. MAS spectra were performed at $14 \mathrm{kHz}$ with a Bruker $4 \mathrm{~mm}$ MAS probes using a simple sequence ( $\tau$ - acquisition). The processing and acquisition parameters were recycle time $5 \mathrm{~s}, 5 \mu$ s single $\pi / 2$ pulse duration and 64 scans. The ${ }^{1} \mathrm{H}$ chemical shifts are given in ppm and refer to tetramethylsilane (TMS) by using adamantane as an external standard (1.74 ppm from TMS). The reproducibility of the measured chemical shift values was of around $0.1 \mathrm{ppm}$.

\subsection{X-rays fluorescence}


X-rays fluorescence measurements have been realised on the three as-synthesized samples. Measurements have been performed in a semi-quantitative multi-elements analysis on a Bruker AXS S4 Pioneer equipment. The three samples present quite the same purity level with the same impurities (see Table 1). Magnesium is the main impurity presents at around $0.5 \mathrm{wt} \%$ expressed in elementary oxide: $0.41 \mathrm{wt} \% \mathrm{of} \mathrm{MgO}$ in GCC, 0.58 wt $\%$ in PCC- 1 and $0.50 \mathrm{wt} \%$ in PCC-2. The others impurities are minors, with levels below $0.4 \mathrm{wt} \%$ for $\mathrm{P}_{2} \mathrm{O}_{5}$, below 0.2 wt $\%$ for $\mathrm{SiO}_{2}$, and even below 0.1 wt \% for $\mathrm{Al}_{2} \mathrm{O}_{3}, \mathrm{SrO}, \mathrm{SO}_{3}$ and $\mathrm{Fe}_{2} \mathrm{O}_{3}$, when applicable.

\section{Results and discussion}

\subsection{Thermal analyses}

The two weight losses observed at about $525 \mathrm{~K}$ and $725 \mathrm{~K}$ in case of PCCs are shown in Figure 1 by TGA and derivative curves. These two thermal events were characteristic of PCCs, as indicated by a comparison with the GCC TGA curve presenting only the monotonic weight loss from RT up to carbonate decomposition. The calculated weight loss values relative to each event were not the same in the two PCCs: PCC-1 weight losses were significantly larger than the PCC-2 weight losses: respectively $0.79 \mathrm{wt} \%$ and $0.24 \mathrm{wt} \%$ at around $525 \mathrm{~K}$ for respectively PCC- 1 and PCC-2, and $0.59 \mathrm{wt} \%$ and $0.06 \mathrm{wt} \%$ at around 725 $\mathrm{K}$ for respectively PCC-1 and PCC-2. In the case of GCC, a very small weight loss of about $0.02 \mathrm{wt} \%$ can be observed for the first thermal event at around $525 \mathrm{~K}$. A good agreement was found between TGA and KF analyses for the three samples (Table 2), bringing evidence for the assignment of the two weight losses to water releases. The higher values found for the PCCs by KF compared to TGA were due to a static thermal process versus a dynamical one by TGA. On the other hand, variations of the physisorbed water level due to storage conditions were not excluded. The smaller value obtained by KF for the GCC sample between 393 and $573 \mathrm{~K}(0.08 \%$ versus $0.16 \%)$ proves the contribution of the decarbonation process to the monotonic loss above $393 \mathrm{~K}$. Thermal analyses coupled with mass spectroscopy on PCCs confirmed these attributions to water release by evidencing two peaks coming from the $\mathrm{OH}^{+}$ signal at $525 \mathrm{~K}$ and $725 \mathrm{~K}$ [6]. Figure 2 indicates the weight losses calculated from TGA at $525 \mathrm{~K}$ (i.e. exclusively due to the first water release) and at $725 \mathrm{~K}$ (i.e. exclusively due to the second water release) according to the previously applied thermal treatment. The indicated water loss values in Figure 2 were obtained after removal, from TGA curves, of their own continuously monotone weight loss. This monotonic weight loss was extrapolated in two 
steps: $i$ / from a linear fit of the weight decrease from $300 \mathrm{~K}$ up to $455 \mathrm{~K}$ (the subtraction of this linear fit from the TGA curve, over the whole thermal range, allowed the determination of the weight loss corresponding only to the first thermal event); ii/ followed by a new linear fit performed on the as-obtained curve from $600 \mathrm{~K}$ up to $675 \mathrm{~K}$ (the new subtraction of the second linear fit allowed the determination of the weight loss corresponding only to the second thermal event). Not only the amounts of water losses did vary from one PCC to another, but also the ratio between the first and the second releases did. From 1.34 for PCC-1, it increased to 4.00 for PCC-2. Figure 2 illustrates also the irreversibility of both water releases: samples thermally treated above the thermal event did not show the corresponding weight loss anymore, contrarily to the reversible monotonic weight loss that was always observable for all the thermally treated samples, as usual with physisorbed water. As a matter of fact, PCCs usually contain a higher amount of surface adsorbed water molecules because of their higher specific surface areas compared to GCC: in our case, respectively $7 \mathrm{~m}^{2} \cdot \mathrm{g}^{-1}, 26$ $\mathrm{m}^{2} \cdot \mathrm{g}^{-1}$ and $3 \mathrm{~m}^{2} \cdot \mathrm{g}^{-1}$ for samples PCC-1, PCC-2 and GCC, as measured by nitrogen at $77 \mathrm{~K}$ after an outgasing step at $120{ }^{\circ} \mathrm{C}$ (BET method, see Table 1). Moreover, the level of physisorbed water (Table 2) correlated well with the BET specific surface area extend. The water release observed at around $725 \mathrm{~K}$ should correspond to hydroxyl condensation of portlandite $\mathrm{Ca}(\mathrm{OH})_{2}$. The calculated weight losses led to portlandite amounts of $2.43 \mathrm{wt} \%$ and $0.25 \mathrm{wt} \%$ for respectively PCC-1 and PCC-2. These amounts indicated that portlandite could be detected by powder X-rays diffraction for PCC-1, but not in the case of PCC-2, whose $\mathrm{Ca}(\mathrm{OH})_{2}$ amount was clearly too small.

\subsection{Rietveld analyses of the powder X-rays diffraction patterns}

Rietveld analyses were performed for each as-synthesized samples and each thermally treated PCC-1, PCC-2 and GCC samples. Four phases were simulated as follow: i/ silicon Si (internal standard), ii/ calcite $\mathrm{CaCO}_{3}$ (largely majority phase), iii/ portlandite $\mathrm{Ca}(\mathrm{OH})_{2}$ (when observed) and $\mathrm{iv} / \mathrm{lime} \mathrm{CaO}$ (when observed for thermal treatment above $725 \mathrm{~K}$ ). Portlandite was identified in PCC-1 for thermal treatments above $475 \mathrm{~K}$. It disappeared at $775 \mathrm{~K}$ and lime was observed. Figure 3 shows the evolution of the refined diffraction powder patterns when heating PCC-1. Careful analysis of low intensity peaks (see inserts in Figure 3) revealed that portlandite was not visible in the as-synthesized PCC-1 sample. No change was observed for treatments up to $425 \mathrm{~K}$ (powder patterns still correspond to top of Figure 3). Next, portlandite was identified for treatments between $475 \mathrm{~K}$ and $725 \mathrm{~K}$, 
namely by broad diffraction peaks at $2 \theta=18.0^{\circ}$ and $34.2^{\circ}$ (powder patterns corresponding to middle of Figure 3). Finally, at $775 \mathrm{~K}$, diffraction peaks of portlandite disappeared and those of lime appeared (powder pattern corresponding to bottom of Figure 3 with broad peaks of $\mathrm{CaO}$ at $2 \theta=32.1^{\circ}$ and $37.3^{\circ}$ ). This confirms that the second thermal event observed at about $725 \mathrm{~K}$ corresponds to the dehydroxylation of portlandite. It means that $\mathrm{Ca}(\mathrm{OH})_{2}$ is present in small amounts in PCCs, but not in GCC. In course of the PCC synthesis, few weight percent of amorphous $\mathrm{Ca}(\mathrm{OH})_{2}$ were precipitated together with $\mathrm{CaCO}_{3}$ formation. A heating treatment of almost $475 \mathrm{~K}$ led to its crystallization. The broad diffraction peaks of $\mathrm{Ca}(\mathrm{OH})_{2}$ indicated its very small coherent domain size (Table 3). The starting temperature of $\mathrm{Ca}(\mathrm{OH})_{2}$ crystallisation (i.e. $475 \mathrm{~K}$ according to the 15 hours thermal treatment) was close to the first thermal event (i.e. $525 \mathrm{~K}$ according to dynamical TGA experiments). These two simultaneous events (water release and portlandite crystallisation) could either be dependent or independent. In the hypothesis of dependent events it should indicate that amorphous portlandite contained excess water

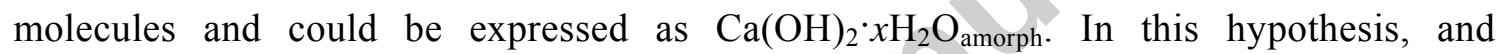
according to TGA results, the $x$ value would be of about 1.34 and 4.00 for PCC-1 and PCC-2, respectively. Refinement on diffraction patterns from PCC-2 and GCC did not allow the identification of portlandite. In case of PCC-2, the weight loss of $0.06 \mathrm{wt} \%$ observed at $725 \mathrm{~K}$ led to an amount of $0.25 \mathrm{wt} \%$ of $\mathrm{Ca}(\mathrm{OH})_{2}$, which is to small to be detectable by X-rays diffraction, even after crystallisation. In relation to GCC, no portlandite could be detected since no weight loss appeared in TGA at around $725 \mathrm{~K}$.

Figure 4 shows the evolution of calcite refined parameters as a function of the thermal treatments. PCCs did not show the same behaviour as GCC. X-rays fluorescence results on GCC and PCCs indicated that differences between samples could not been explained by the presence of impurities like $\mathrm{Mg}, \mathrm{Si}, \mathrm{Al}$ or Sr. Contrary to PCCs, the GCC lattice parameters were not sensitive to thermal treatments. In case of PCC lattice parameters evolution, we observed a break at $475 \mathrm{~K}$. Before $475 \mathrm{~K}$, the unit cell volume of PCC was superior to the one of GCC (and unit cell volume of PCC-1 is superior to the one of PCC2 ), and after the break at $475 \mathrm{~K}$ the three samples converged on the same unit cell volume. Positions of oxygen site in PCCs and GCC showed also some interesting evolutions (Table 3). Refined $x$ coordinate of oxygen site in as-synthesized PCC and GCC samples were different (0.258 for as-synthesized PCC-1 and PCC-2 compared to 0.252 for assynthesized GCC), but became equivalent after $525 \mathrm{~K}(0.257,0.257$ and 0.258 for respectively PCC-1, PCC-2 and GCC thermally treated at $575 \mathrm{~K}$ ). This led to interesting 
evolution of the inter-atomic $\mathrm{d}_{\mathrm{Ca}-\mathrm{O}}$ distances: smaller in PCCs below $525 \mathrm{~K}$, and identical in PCCs and GCC above $525 \mathrm{~K}$. These several observations on calcite structure parameters showed that $\mathrm{CaCO}_{3}$ was affected by the first water release at around $525 \mathrm{~K}$. It indicated that the first thermal event was due to a release of water molecules coming from the calcite structure: water inserted in the calcite structure as a limited solid solution $\mathrm{CaCO}_{3}-\mathrm{H}_{2} \mathrm{O}$. The previous hypothesis of excess water in amorphous $\mathrm{Ca}(\mathrm{OH})_{2} \cdot \mathrm{H}_{2} \mathrm{O}_{\text {amorph }}$ could not explain the observed variations in calcite structure parameters but, at this stage, we can not exclude the presence of some $\mathrm{Ca}(\mathrm{OH})_{2} \cdot x \mathrm{H}_{2} \mathrm{O}_{\text {amorph }}$ though. 'Structural' water molecules inserted in the $\mathrm{CaCO}_{3}$ network induced a repulsive interaction with the oxygen coordinated to calcium atoms, leading to the refined small contraction of the $\mathrm{d}_{\mathrm{Ca}-\mathrm{O}}$ distance in PCCs (compared to GCC), which disappeared after $525 \mathrm{~K}$. The calcite composition can be expressed as $\mathrm{CaCO}_{3} \cdot y \mathrm{H}_{2} \mathrm{O}$ with $y=0.04$ and 0.01 , for respectively $\mathrm{PCC}-1$ and PCC-2 samples. A very small weight loss was also observed for GCC at $525 \mathrm{~K}$, corresponding to the composition $\mathrm{CaCO}_{3} \cdot 0.001 \mathrm{H}_{2} \mathrm{O}$. As-synthesized PCCs contain small amounts of amorphous portlandite and small amounts of water molecules inserted in their own crystallographic structure. Microstructure parameters did not show important changes according to the thermal treatment.

\subsection{Vibrations}

Vibrational spectroscopies, DRIFT and Raman, were performed on the three assynthesized samples and on some thermally treated samples (mainly PCC-1 treated at around $525 \mathrm{~K}$ ). Figure 5 shows the wavenumber range $4000 \mathrm{~cm}^{-1}-2000 \mathrm{~cm}^{-1}$ (water and hydroxyl vibrations, along with calcite overtone and combination modes coming from lattice or multiphonon absorptions [11]) and a zoom around $3644 \mathrm{~cm}^{-1}\left(\mathrm{~A}_{2 \mathrm{u}}\right.$ asymmetric stretching mode of hydroxyls in portlandite). Figure 6 shows two zooms, around $1087 \mathrm{~cm}^{-}$

${ }^{1}$ ( $\mathrm{A}_{1 \mathrm{~g}}$ vibration mode of carbonate in calcite) and $3620 \mathrm{~cm}^{-1}\left(\mathrm{~A}_{1 \mathrm{~g}}\right.$ symmetric stretching mode of hydroxyl in portlandite) from the Raman spectra. Observations on hydroxyl vibrations modes were in perfect agreement with previously identified portlandite crystallisation. Asymmetric stretching at $3644 \mathrm{~cm}^{-1}$ on DRIFT spectra and symmetric stretching at $3620 \mathrm{~cm}^{-1}$ on Raman spectra are characteristic of portlandite $[12,13]$ and in agreement with measurements performed on pure $\mathrm{Ca}(\mathrm{OH})_{2}$ samples, not shown here. As observed by X-rays diffraction, the signal of portlandite increased upon thermal treatment, indicating its crystallization process which occurred between $475 \mathrm{~K}$ and $500 \mathrm{~K}$. Before 
this temperature treatment, the hydroxyl vibrations bands were already observable, but with a weaker intensity. This confirmed that $\mathrm{Ca}(\mathrm{OH})_{2}$ was already present in the assynthesized samples but with a low crystallinity; i.e. amorphous state according to long range order necessary for X-rays diffraction. In its amorphous state, and due to hydrogen bonding, $\mathrm{Ca}(\mathrm{OH})_{2}$ hydroxyl vibrations can not be easily detected because they should rather give rise to much broader signals occuring at a lower wavenumber than $3644 \mathrm{~cm}^{-1}$ in the DRIFT spectra (means within the broad water band centered at $3450 \mathrm{~cm}^{-1}$ ) or than $3620 \mathrm{~cm}^{-1}$ in the Raman spectra. The evolution of the relative amount of detected portlandite, respectively in DRIFT and Raman studies, was determined by the integrated peak area corresponding respectively to the $\mathrm{A}_{2 \mathrm{u}}\left(\mathrm{OH}^{-}\right)$and $\mathrm{A}_{1 \mathrm{~g}}\left(\mathrm{OH}^{-}\right)$modes from portlandite. In both cases, the maximum calculated peak area was assigned to a relative amount of 1.00. Table 4 indicates the calculated relative amounts (see also Figure 7) of portlandite together with the absolute values deduced from TGA and PDRX experiments. The differences between TGA relative values and the three other series come from the amorphous features of portlandite before $475 \mathrm{~K}$.

The extremely broad band in DRIFT spectra, with maximum at around $3450 \mathrm{~cm}^{-1}$, corresponds to stretching vibrations of hydroxyl bonds which could be assigned to four different species: $i /$ hydrogen bonded physisorbed water; $i i /$ water inserted in the calcite structure (hydrogen bonded 'structural' water, $\mathrm{CaCO}_{3} \cdot \mathrm{yH}_{2} \mathrm{O}$ ); iii/ over-stoechiometric water from amorphous portlandite $\left(\mathrm{Ca}(\mathrm{OH})_{2} \cdot \mathrm{xH}_{2} \mathrm{O}_{\text {amorph }}\right)$ hydrogen bonded; and iv/ hydrogen bonded hydroxyls from amorphous portlandite. The number of species involved in this band makes its use inappropriate. Besides, the use of the bending mode of water near $1620 \mathrm{~cm}^{-1}$ was not be possible due to the strong underlying carbonate modes in this region. Moreover, the use of the first $(v+\delta)$ water combination band at around $5200 \mathrm{~cm}^{-1}$ [14], which eliminates the contribution of hydroxyls from the amorphous portlandite, was not possible either because of the different kind of water involved and as well because this spectral range is strongly dominated by the physisorbed water contribution, whose level is higher. This explained as well the differences in the intensity of the band at $3450 \mathrm{~cm}^{-1}$, as seen in Figure 5 left, where it was more important in PCC-1 and quasi-absent in GCC, in good agreement with the physisorbed water level from KF (Table 2) and the specific surface areas (Table 1). Finally, neither the mid infrared range (3450 or $1620 \mathrm{~cm}^{-1}$ ) nor the near infrared one (near $5200 \mathrm{~cm}^{-1}$ for sole water contribution - no other changes relative to pure $\mathrm{Ca}(\mathrm{OH})_{2}$ hydroxyl contributions were seen in this range either, like between 4800 
and $\left.4000 \mathrm{~cm}^{-1}[14]\right)$ were usable to confirm the presence of excess water in the amorphous portlandite.

The Raman spectra on $\mathrm{CO}_{3}{ }^{2-} \mathrm{A}_{1 \mathrm{~g}}$ symmetric stretching vibration mode at $1087 \mathrm{~cm}^{-1}$, characteristic of calcite [11], showed a sharpening of HWHM (half width at half maximum, as presented in Table 4) for samples thermally treated above $500 \mathrm{~K}$. This indicates an increase of the local environment homogeneity of carbonate anions in the calcite structure. This observation is in agreement with the departure of some inserted water molecules from the calcite structure, and cannot be explained by the crystallisation process of portlandite, in agreement with the PXRD analyses.

\subsection{Solid state ${ }^{1}$ H MAS NMR}

Solid state ${ }^{1} \mathrm{H}$ MAS NMR spectroscopy was performed on the three as-synthesised samples and on thermally treated PCC-1 samples at $425 \mathrm{~K}, 475 \mathrm{~K}, 575 \mathrm{~K}$ and $725 \mathrm{~K}$ (Figure 8). Spectra from as-synthesised samples (top of Figure 8) underline the differences between PCC and GCC samples. Whereas free water was visible on the GCC spectrum by the line centred at chemical shift $4.8 \mathrm{ppm} / \mathrm{TMS}$ (indicated by a star in Figure 8 ), two other contributions centred at $8.6 \mathrm{ppm}$, and as well relative to water (one broad and one sharp part), are also present in the GCC spectrum. The two PCC spectra both exhibit one sharp signal at $10.3 \mathrm{ppm}$ and one broad line with a higher area centred close to $9.0 \mathrm{ppm}$ (9.1 ppm for PCC-1 and $8.7 \mathrm{ppm}$ for PCC-2). A first interpretation of these ${ }^{1} \mathrm{H}$ NMR spectra seems to assign the fixed sharp contribution at $10.3 \mathrm{ppm}$ to water inserted in the calcite structure and the broad contribution close to $9.0 \mathrm{ppm}$ to amorphous $\mathrm{Ca}(\mathrm{OH})_{2}$. It must be noted that the well resolved spinning side bands were relative to the line at 10.3 ppm. Two facts can explain the sharpness of the line at $10.3 \mathrm{ppm}$ : $i /{ }^{1} \mathrm{H}$ nuclei were diluted in the $\mathrm{CaCO}_{3} \cdot y \mathrm{H}_{2} \mathrm{O}$ solid solution resulting in a lowering of the ${ }^{1} \mathrm{H}-{ }^{1} \mathrm{H}$ homonuclear dipolar coupling and then in a narrower line, ii/ the well-ordered crystalline structure reduced the possible number of slightly different environments, leading also to line width reduction. The spectrum obtained with a commercial portlandite sample is shown at the bottom of Figure 8 (dotted line). The crystallized $\mathrm{Ca}(\mathrm{OH})_{2}$ spectrum (extremely broad band at $5.1 \mathrm{ppm}$ ) was different from the contributions observed in the PCC samples. Nevertheless, this difference can be explained by the difference in crystallinity: in well crystallized $\mathrm{Ca}(\mathrm{OH})_{2}$, the proton coupling is optimized involving a line broadening of the band. ${ }^{1} \mathrm{H}$ NMR observations on thermally treated PCC-1 samples 
agreed with these interpretations. Changes in the ${ }^{1} \mathrm{H}$ NMR spectrum after a treatment at $425 \mathrm{~K}$ were low. On the contrary, drastic changes appeared for a treatment at $475 \mathrm{~K}$ : large decrease in intensity of the contribution at $10.3 \mathrm{ppm}$, in addition to sharpening and shift of the most important peak from $9.1 \mathrm{ppm}$ to $8.9 \mathrm{ppm}$. Treatment at $575 \mathrm{~K}$ led to the same observations. The sharp contribution at $10.3 \mathrm{ppm}$ significantly decreased and the main band centred at $8.8 \mathrm{ppm}$ became sharper. Another broad contribution was well observable at $5.0 \mathrm{ppm}$ chemical shift: it can be assigned to well crystallized portlandite. The spectrum from sample PCC-1 treated at $725 \mathrm{~K}$ showed the disappearance of the main band at 8.8 ppm and the broad band at $5.0 \mathrm{ppm}$. Taking into account the presence of their spinning side bands and their disappearance at $475 \mathrm{~K}$ (beginning of the first water release) the sharp band at $10.3 \mathrm{ppm}$ was indeed assigned to water molecules inserted in the calcite structure. The broad line close to $9.0 \mathrm{ppm}$ which became sharper and sharper, before disappearing at $725 \mathrm{~K}$ (temperature of the second water release), was indeed assigned to amorphous portlandite.

The ${ }^{1} \mathrm{H}$ NMR signal of $\mathrm{Ca}(\mathrm{OH})_{2}$ contained in PCCs was different from the one of commercial portlandite by both a shift of the maximum peak and its sharpness. Two facts had to be considered: i) the hydrogen bonds network could be completely different in $\mathrm{Ca}(\mathrm{OH})_{2} \cdot x \mathrm{H}_{2} \mathrm{O}_{\text {amorph }}$ before crystallization of portlandite, ii) the nanometric feature of crystalline $\mathrm{Ca}(\mathrm{OH})_{2}$ in PCCs after $525 \mathrm{~K}$ (as indicated by PDRX patterns and Rietveld refinements) can decrease the ${ }^{1} \mathrm{H}-{ }^{1} \mathrm{H}$ coupling. Nevertheless, an amount of well crystallized portlandite was observable by the broad signal at $5.0 \mathrm{ppm}$ after a treatment at $575 \mathrm{~K} .{ }^{1} \mathrm{H}$ NMR experiments showed again the simultaneity of the two phenomena upon heating: disappearance of the contribution of structural water inserted in the calcite $\mathrm{CaCO}_{3} \cdot y \mathrm{H}_{2} \mathrm{O}$, simultaneously with the crystallisation process of portlandite. But no evidences were brought about the possible excess water present in amorphous portlandite $\mathrm{Ca}(\mathrm{OH})_{2} \cdot \times \mathrm{H}_{2} \mathrm{O}_{\text {amorph }}$.

\section{Conclusion}

Three distinct water releases were observed in PCCs: one monotonic up to the carbonate dissociation, and two thermal events at $525 \mathrm{~K}$ and $725 \mathrm{~K}$. Solid state ${ }^{1} \mathrm{H}$ MAS NMR spectroscopy confirmed the existence of three sets of proton in PCCs, leading to three different natures of water. The water content in PCCs is sample dependent, which means synthesis dependant. A complete characterization of these PCC water releases should give 
information about their natures, and subsequently information about the improvements to implement in the PCC synthesis process. The monotonic water release has been associated to physisorbed surface water molecules and early decarbonation (also present in case of GCCs). Identification of the second thermal event at around $725 \mathrm{~K}$ was clearly assigned to portlandite $\mathrm{Ca}(\mathrm{OH})_{2}$ dehydroxylation. $\mathrm{Ca}(\mathrm{OH})_{2}$ was present and at amorphous state in the as-synthesized PCCs. Its crystallisation happened at about $525 \mathrm{~K}$ (Figure 7), simultaneously with the first water release. These two simultaneous phenomena were not linked. PXRD (Figure 4) and Raman spectroscopy (right insert, Figure 7) gave indication about the nature of the first water release which results from departure of water molecules inserted in the calcite structure. The reaction occurring at $525 \mathrm{~K}$ was $\mathrm{CaCO}_{3} \cdot y \mathrm{H}_{2} \mathrm{O} \rightarrow$ $\mathrm{CaCO}_{3}+y \mathrm{H}_{2} \mathrm{O}$. An amount of 0.001 inserted water molecule per mole of $\mathrm{CaCO}_{3}$ was estimated for GCC, and this amount reached 0.01 and 0.04 in case of PCC- 2 and PCC-1 respectively. The compositions of the three commercial studied calcium carbonates were the following: GCC was a ground calcium carbonates composed at $100 \%$ by $\mathrm{CaCO}_{3} \cdot 0.001 \mathrm{H}_{2} \mathrm{O}$, PCC-2 was a precipitated calcium carbonate composed by $0.25 \mathrm{wt} \%$ of amorphous $\mathrm{Ca}(\mathrm{OH})_{2}$ and 99.75 wt $\%$ of $\mathrm{CaCO}_{3} \cdot 0.01 \mathrm{H}_{2} \mathrm{O}$, and $\mathrm{PCC}-1$ was a precipitated calcium carbonate made of 2 wt $\%$ of amorphous $\mathrm{Ca}(\mathrm{OH})_{2}$ and 98 wt $\%$ of $\mathrm{CaCO}_{3} \cdot 0.04 \mathrm{H}_{2} \mathrm{O}$. Physisorbed surface water molecules could not be estimated from the TGA curves as the beginning of the carbonate decomposition contributes also to the monotonic weight loss (simultaneously to the progressive physisorbed water departure).

Besides, we can suppose that the origin of the inserted water present in PCCs was due to the speed of the synthesis process. Referring to the PCCs synthesis reactions (1) and (2) given in the introduction, a less than complete stoichiometric reaction (2) can easily explain the presence of a residue of $\mathrm{Ca}(\mathrm{OH})_{2}$ and a quick precipitation rate during reaction (2) can be at the origin of some $\mathrm{H}_{2} \mathrm{O}$ trapped into the structure of the freshly precipitated calcite.

\section{Acknowledgements}

The authors would like to thank Specialty Minerals Inc. for providing the PCC samples and for giving permission to publish the present results. 


\section{References}

[1] K. Yang, Q. Yang, G. Li, Y. Sun and D. Feng, Mater. Lett., 60(6) (2006) 805, and references therein.

[2] K. K. Mathur and D. B. Vanderheiden, Polymer Modifiers and Additives, Chapt. 5, edited by J. T. Lutz Jr. and R. F. Grossman, Marcel Dekker, 2001.

[3] Y. S. Han, G. Hadiko, M. Fuji and M. Takahashi, J. Eur. Ceram. Soc., 26(4-5) (2006) 843, and references therein.

[4] S. Kobe, G. Drazic, P. J. McGuiness, T. Meden, E. Sarantopoulou, Z. Kollia and A. C. Cefalas, Mater. Sci. Eng. C, 23(6-8) (2003) 811, and references therein.

[5] D. M. Ansari, ECC International Ltd. Patent WO 2000012434.

[6] A. Labrosse, F. Villiéras, Internal Report: "Synthèse, flottation, épuration et morphologie des carbonates de calcium précipités". LEM-GRESD, Nancy, June 1999.

[7] JCPDS - International Centre for Diffraction Data, PDF2 Data Base, release 2001, ID 870673 for portlandite, and ID 88-1807 for calcite.

[8] J. Rodriguez-Carvajal, PROGRAM FullProf.2k - version 3.30, Laboratoire Léon Brillouin (CEA-CNRS), France, 2005 (FullProf.2k manual available on http://wwwllb.cea.fr/fullweb/fp2k/fp2k_divers.htm). See also J. Rodriguez-Carvajal, T. Roisnel, EPDIC-8, 23-26 May 2002, Trans. Tech. Publication Ltd, Uppsala, Sweden, Materials Science Forum 123 (2004) 443.

[9] H. Effenberger, K. Mereiter and J. Zemann, Zeit. Krist., 156 (1981) 233.

[10] H. E. Petch, Acta Cryst., 14 (1961) 950.

[11] W. B. White, in The Infrared Spectra of Minerals, ed. V. C. Farmer, Mineralogical. Society, London, monograph no. 4, 1974, pp. 227-284.

[12] H. D. Lutz, H. Möller and M. Schmitt., J. Mol. Struct., 328 (1994) 121.

[13] O. Oehler and Hs. H. Günthard, J. Chem. Phys. 48, 5 (1968) 2036.

[14] S. J. Gaffey, Jour. Sed. Petrology, 58, 3 (1988), 397-414. 


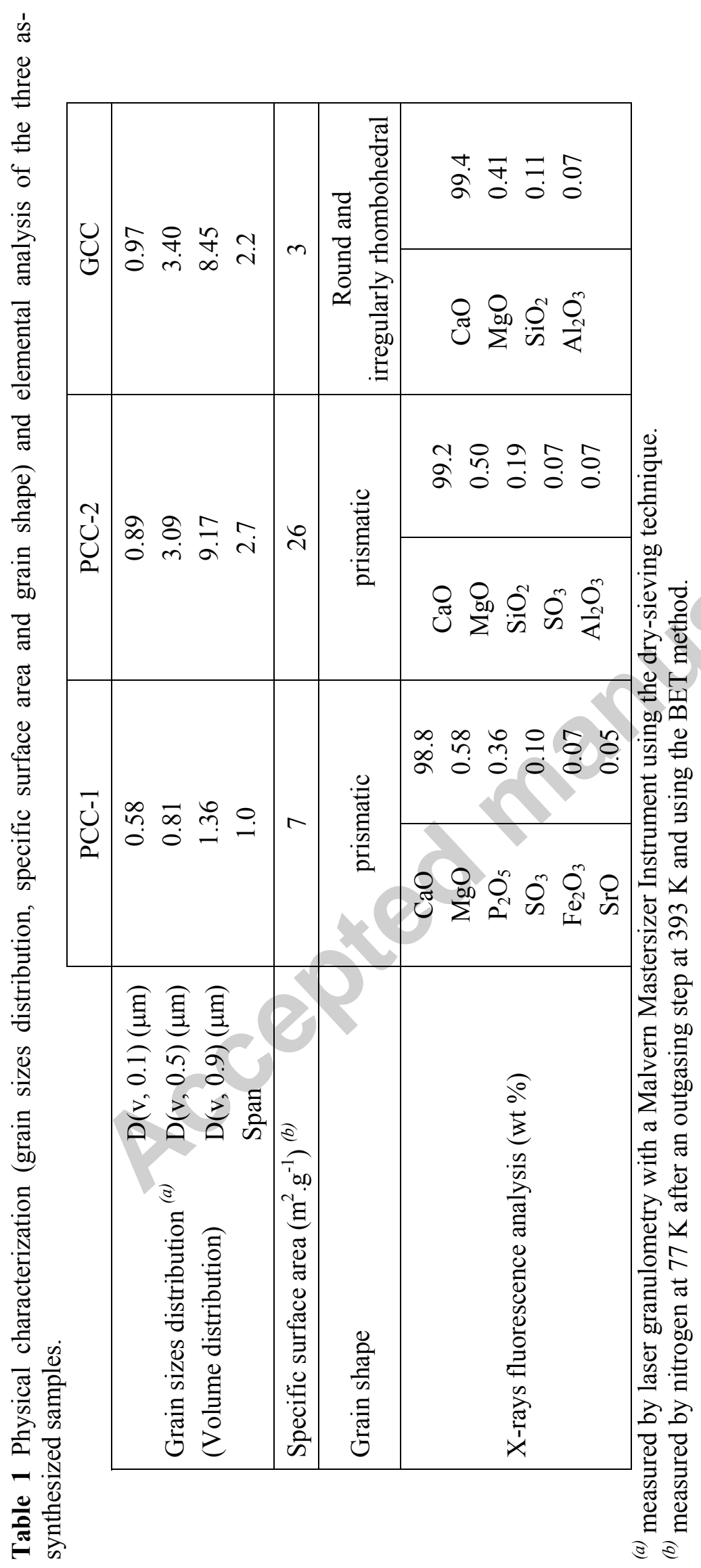




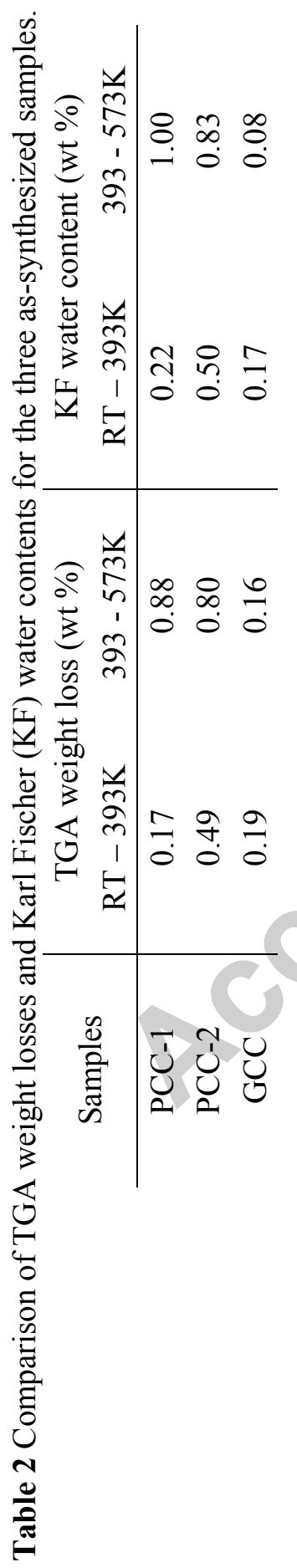




\begin{tabular}{|c|c|c|c|c|}
\hline & 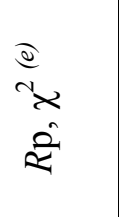 & 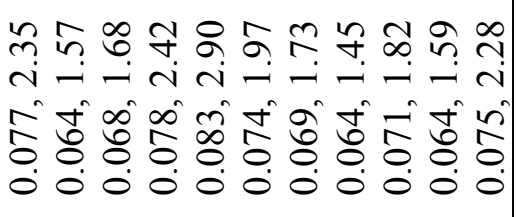 & 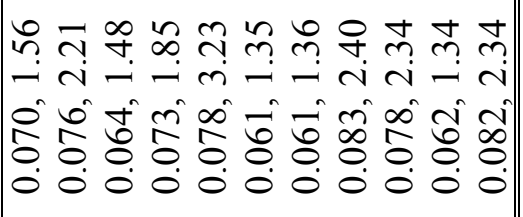 & 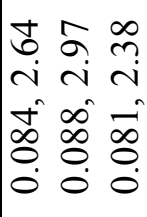 \\
\hline & 毒 & 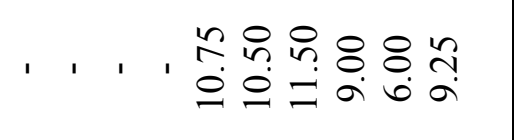 & & \\
\hline 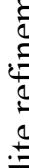 & 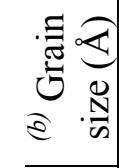 & ' ' ' ' ' 유유요요 & & \\
\hline & 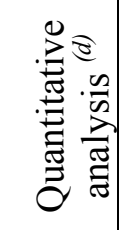 & 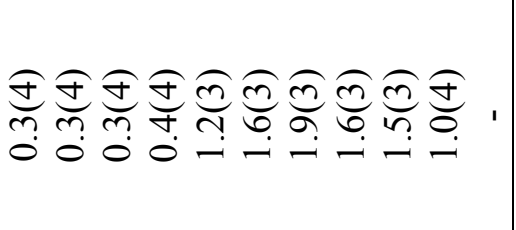 & $\begin{array}{lllllllllll}1 & 1 & 1 & 1 & 1 & 1 & 1 & 1 & 1 & 1 & 1\end{array}$ & 1 \\
\hline & 寻 & 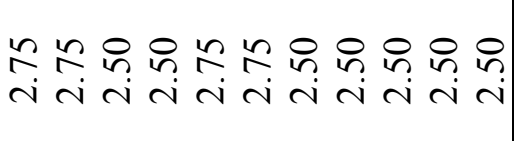 & 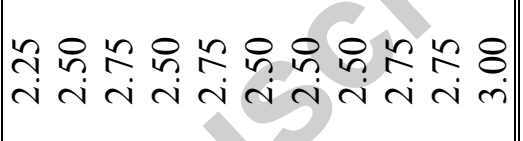 & $\begin{array}{lll}n & n & n \\
& \sim & \sim\end{array}$ \\
\hline & 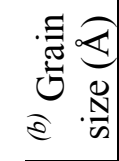 & 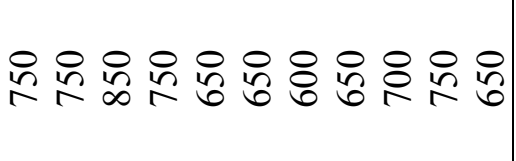 & 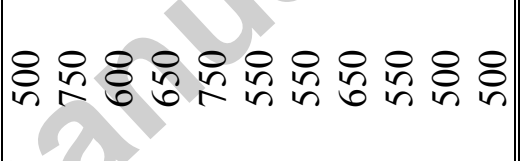 & in \\
\hline & 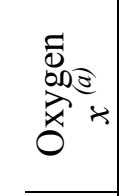 & 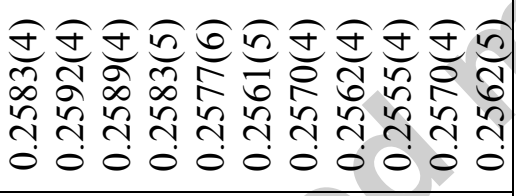 & 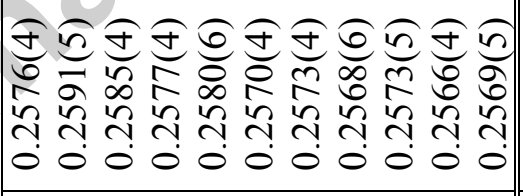 & 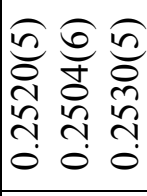 \\
\hline is & $\underset{\substack{\infty \\
o}}{\infty}$ & 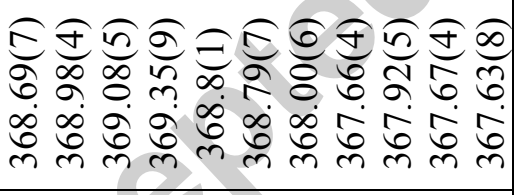 & 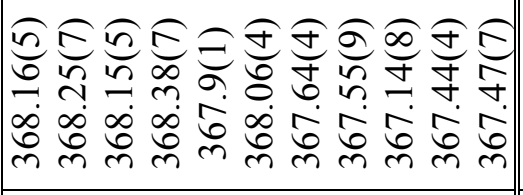 & 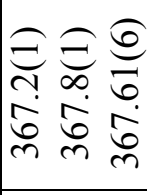 \\
\hline & $\underset{0}{\stackrel{0}{\mathbb{E}}}$ & 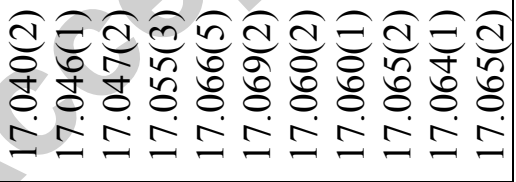 & 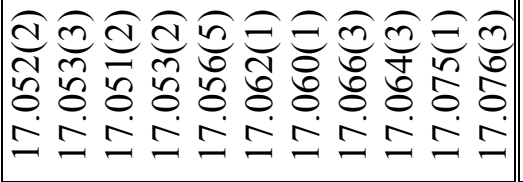 & 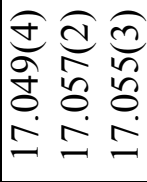 \\
\hline & $\overbrace{0}^{\infty}$ & 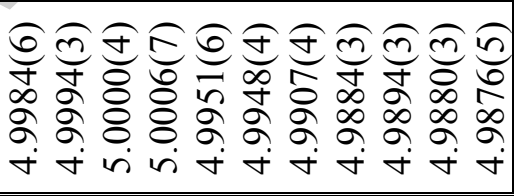 & 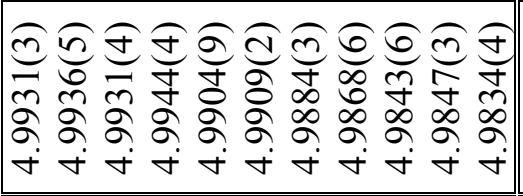 & 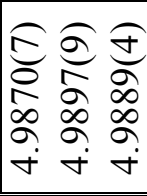 \\
\hline & 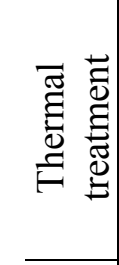 & 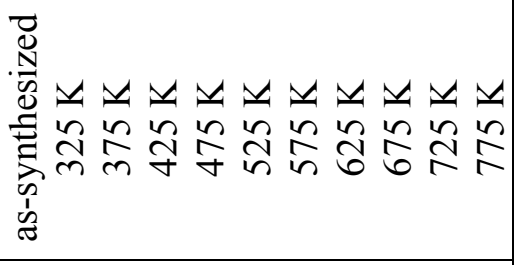 & 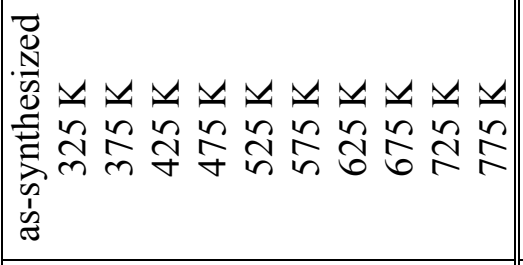 & 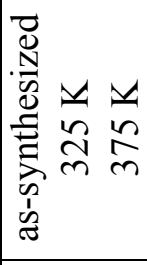 \\
\hline & $\frac{0}{\stackrel{\Xi}{\tilde{E}}}$ & نَ & 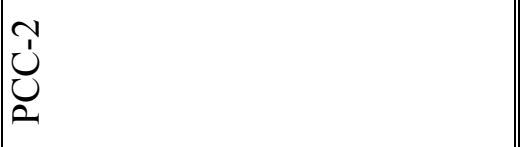 & $\circlearrowright$ \\
\hline
\end{tabular}




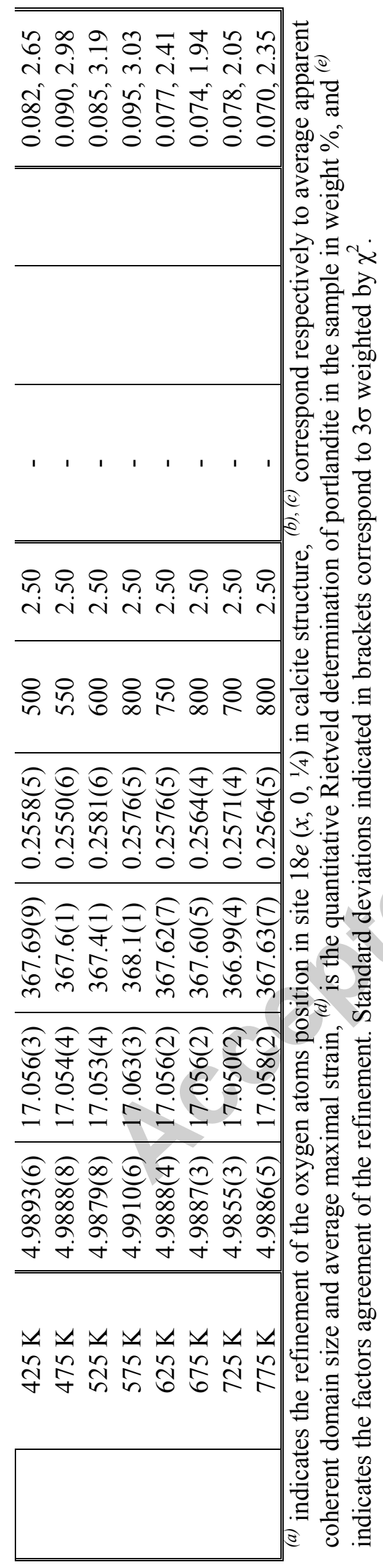




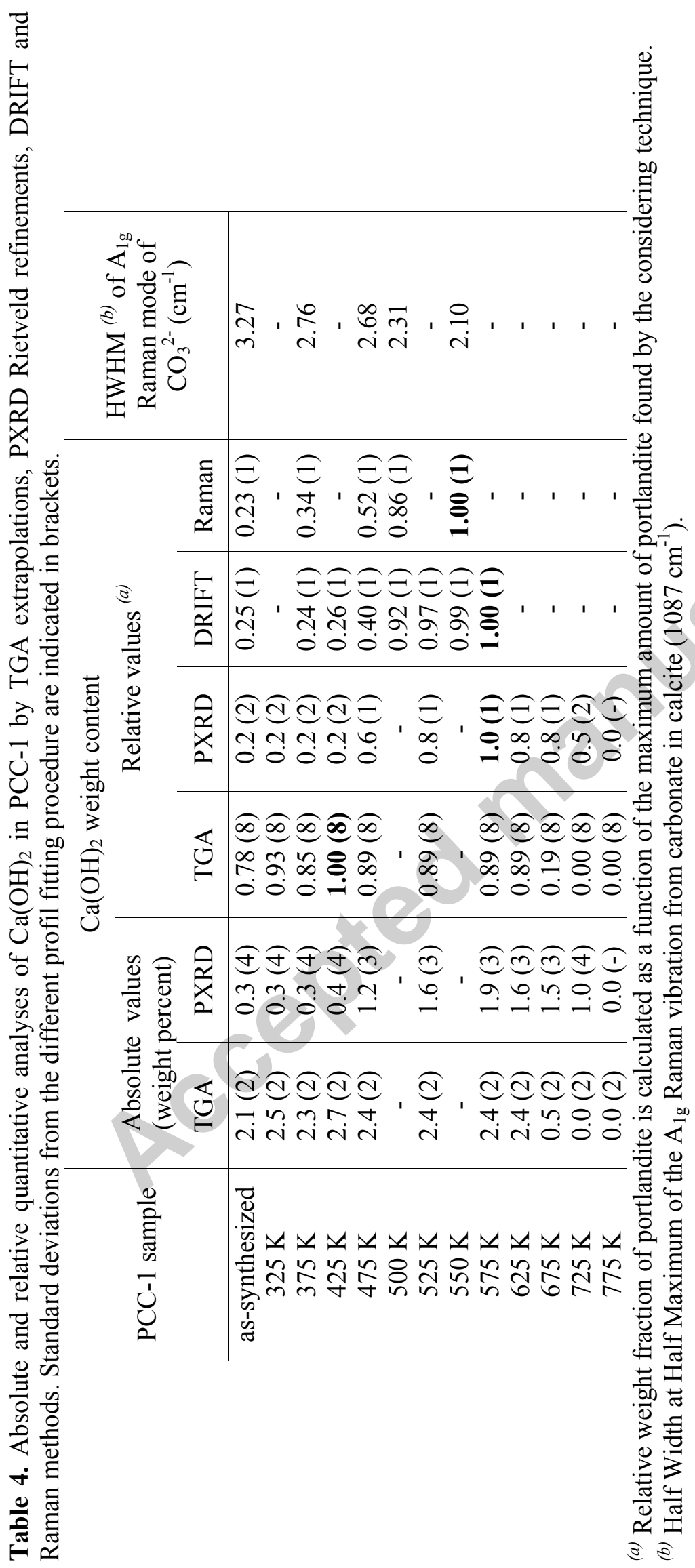




\section{Figures captions}

Figure 1. Thermogravimetric analyses of GCC (A; showing only the monotonic weight loss due to physisorbed water), as-synthesized PCC-1 and PCC-2 (respectively B and C; showing the two studied thermal events superimposed to the monotonic weight loss) from RT up to $825 \mathrm{~K}$. TGA curves (a) and derivative curves (b) are shown.

Figure 2. Weight losses calculated from the TGA curves for the first thermal event at about $525 \mathrm{~K}(\mathrm{a}, \boldsymbol{\square})$ and the second thermal event at about $725 \mathrm{~K}(\mathrm{~b}, \bullet)$ for GCC (A), PCC-1 (B) and PCC-2 (C). The calculations have been performed after removal of the monotonic weight loss (i.e. without taking into account the physisorbed water). Dashed lines are only guides for eyes.

Figure 3. Rietveld plots of as-synthesized PCC-1 (a), thermally-treated at $525 \mathrm{~K}$ (b) and thermally-treated at $775 \mathrm{~K}(\mathrm{c})$. Observed (dots) and calculated (black lines) powder patterns $(\lambda$ $=1.5418 \AA$ Á) are shown with the difference curve (lines above). The ticks indicate the Bragg peak positions of $\mathrm{Si}, \mathrm{CaCO}_{3}, \mathrm{Ca}(\mathrm{OH})_{2}$ and $\mathrm{CaO}$. Small amounts of $\mathrm{Ca}(\mathrm{OH})_{2}$ and $\mathrm{CaO}$ were detected; see arrows in the inserts in (b) and (c).

Figure 4. Rietveld analysis on calcite phase from GCC (A), PCC-1 (B) and PCC-2 (C): evolution of lattice parameter $a(\mathrm{a})$, lattice parameter $c$ (b) and unit cell volume (c). Dashed lines are only guides for eyes.

Figure 5. DRIFT spectra realized on as-synthesized samples (a, range $4000-2000 \mathrm{~cm}^{-1}$ ), and thermally-treated samples $\left(\mathrm{b}\right.$, range $3660-3620 \mathrm{~cm}^{-1}$, with indication of the temperature of treatment, bold lines for as-synthesized samples). Spectra were recorded on GCC (A), PCC-1 (B) and PCC-2 (C).

Figure 6. Raman spectra on PCC-1 thermally-treated at $375 \mathrm{~K}, 475 \mathrm{~K}, 500 \mathrm{~K}$ and $550 \mathrm{~K}$; carbonate vibration from calcite (a, range $1070 \mathrm{~cm}^{-1}$ to $1100 \mathrm{~cm}^{-1}$ ) and hydroxyl stretching mode from portlandite $\left(\mathrm{b}\right.$, range $3500 \mathrm{~cm}^{-1}$ to $\left.3750 \mathrm{~cm}^{-1}\right)$.

Figure 7. Relative weight fraction of portlandite determined by DRIFT, Raman, TGA and PXRD as a function of thermal treatment of PCC-1 (a). Dashed line and dotted curve are only guides for eyes for respectively the total (i.e. amorphous and crystallized) relative amount of portlandite as determined by TGA, and the relative amount of crystallized portlandite as determined by DRIFT, Raman and PXRD. Evolution of the Half Width at Half Maximum (HWHM) of the $\mathrm{A}_{1 \mathrm{~g}}$ carbonate vibration for PCC-1, from the Raman spectra, is shown in insert (b). Error bars correspond to the standard deviations of the different profile fitting procedures.

Figure 8. Solid state ${ }^{1} \mathrm{H}$ MAS NMR spectra on as-synthesized samples (a) and on thermallytreated PCC-1 samples with portlandite $\mathrm{Ca}(\mathrm{OH})_{2}$ (dotted line) as a comparison (b). Spectra (A) correspond to GCC, (B) to PCC-1 and (C) to PCC-2. Stars (*) indicate the contribution of physisorbed water. ' $\mathrm{S}$ ' indicates the position of the spinning sidebands. 
Fig. 1
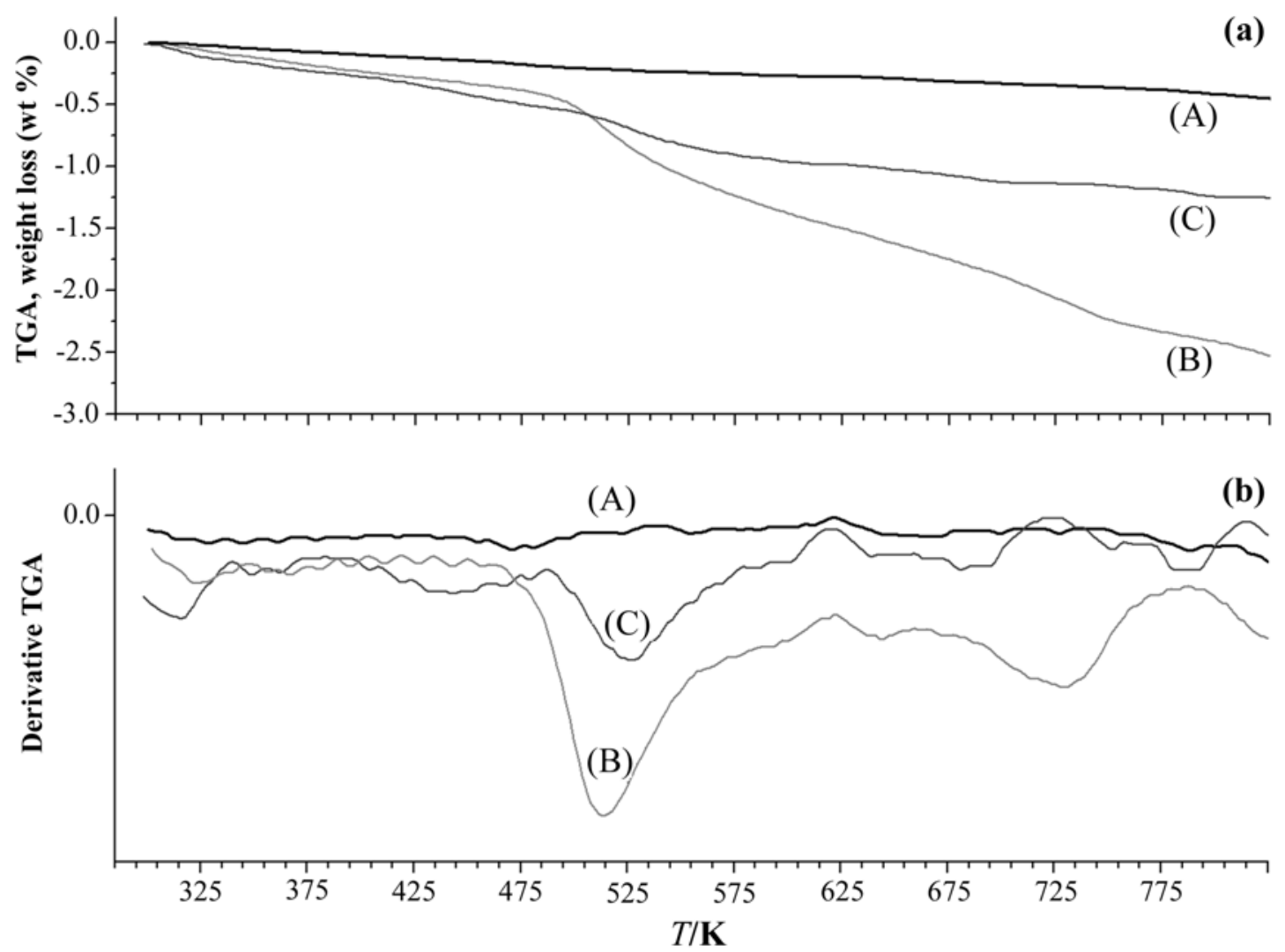
Fig. 2

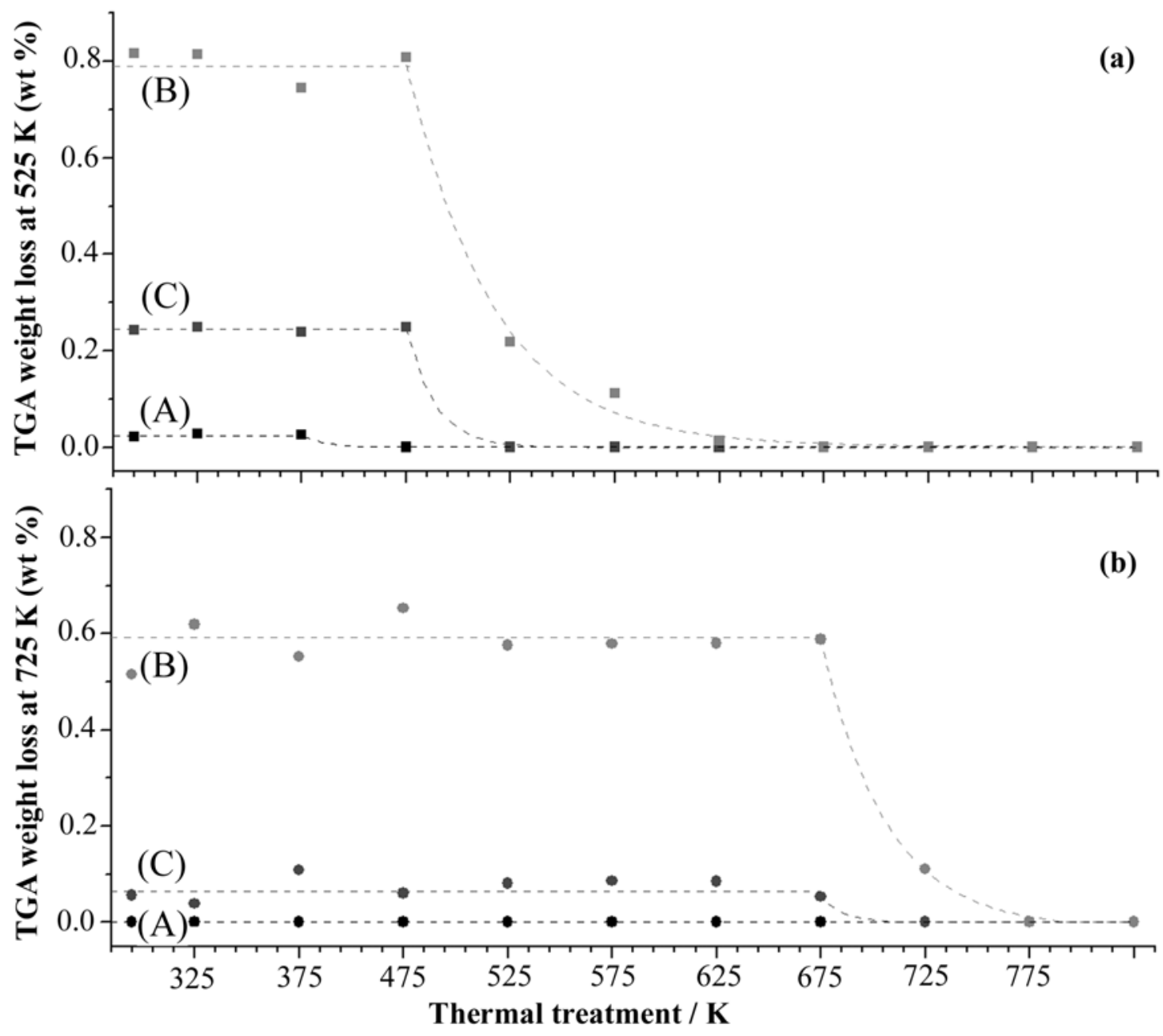


Fig. 3
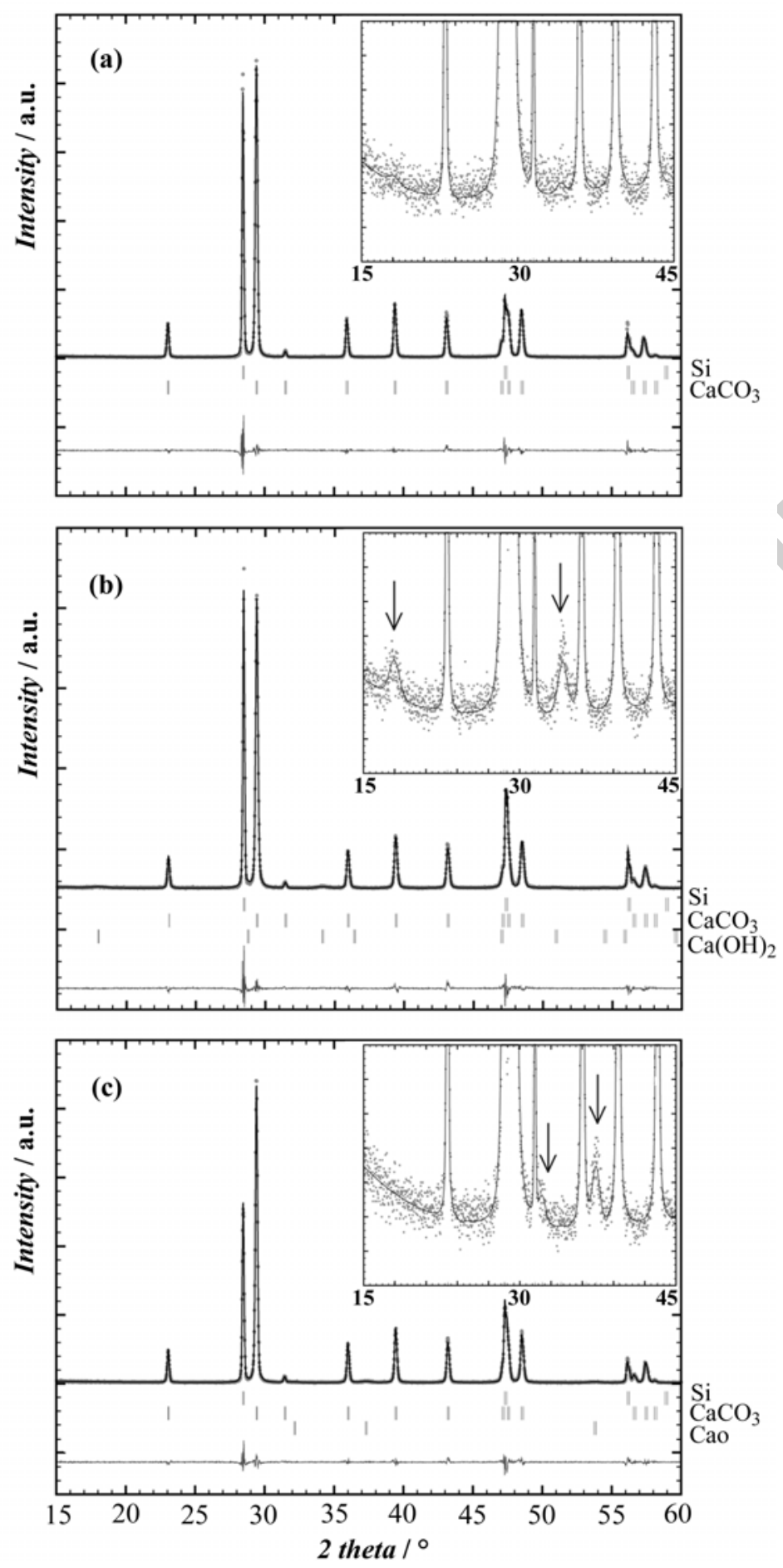
Fig. 4
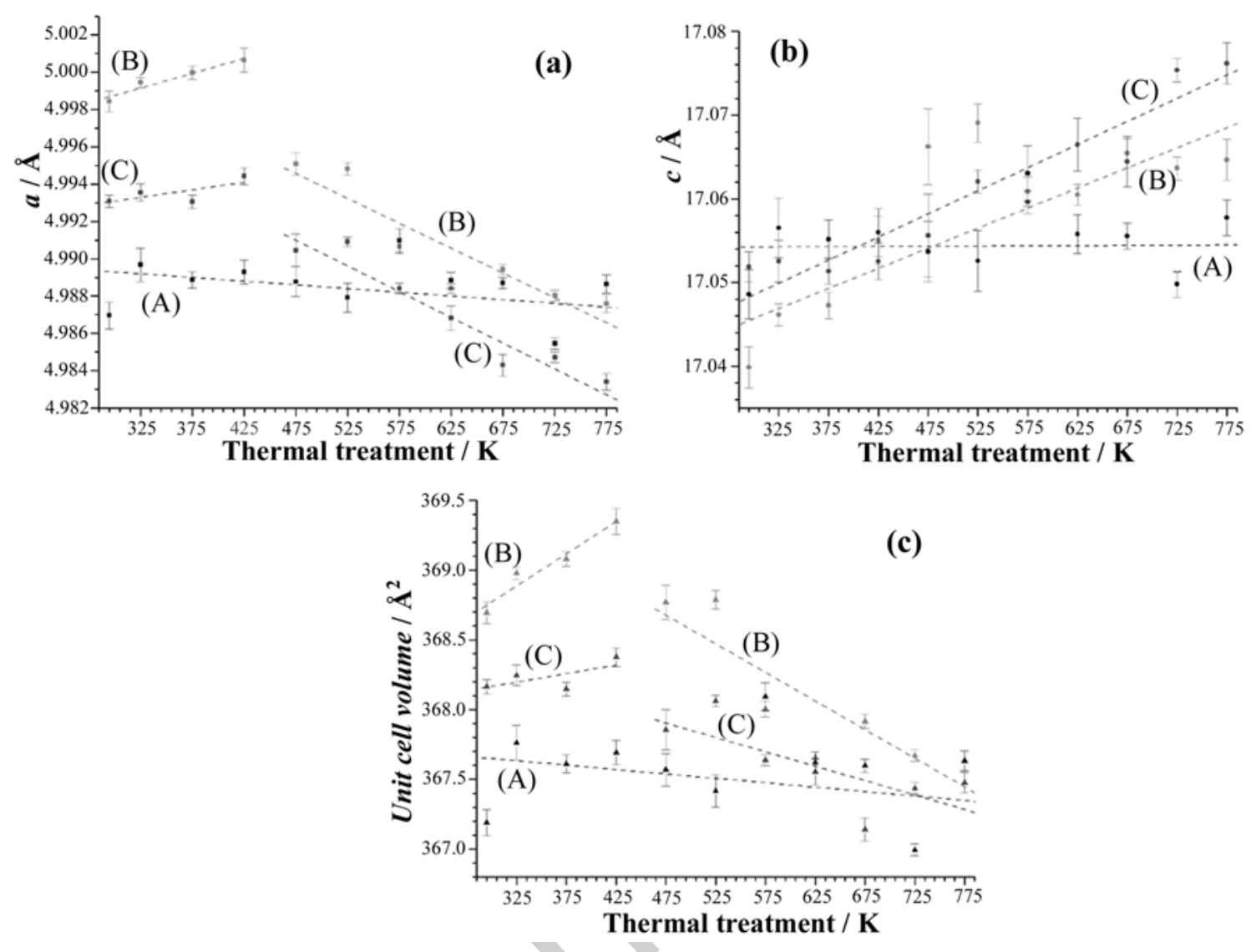
Fig. 5
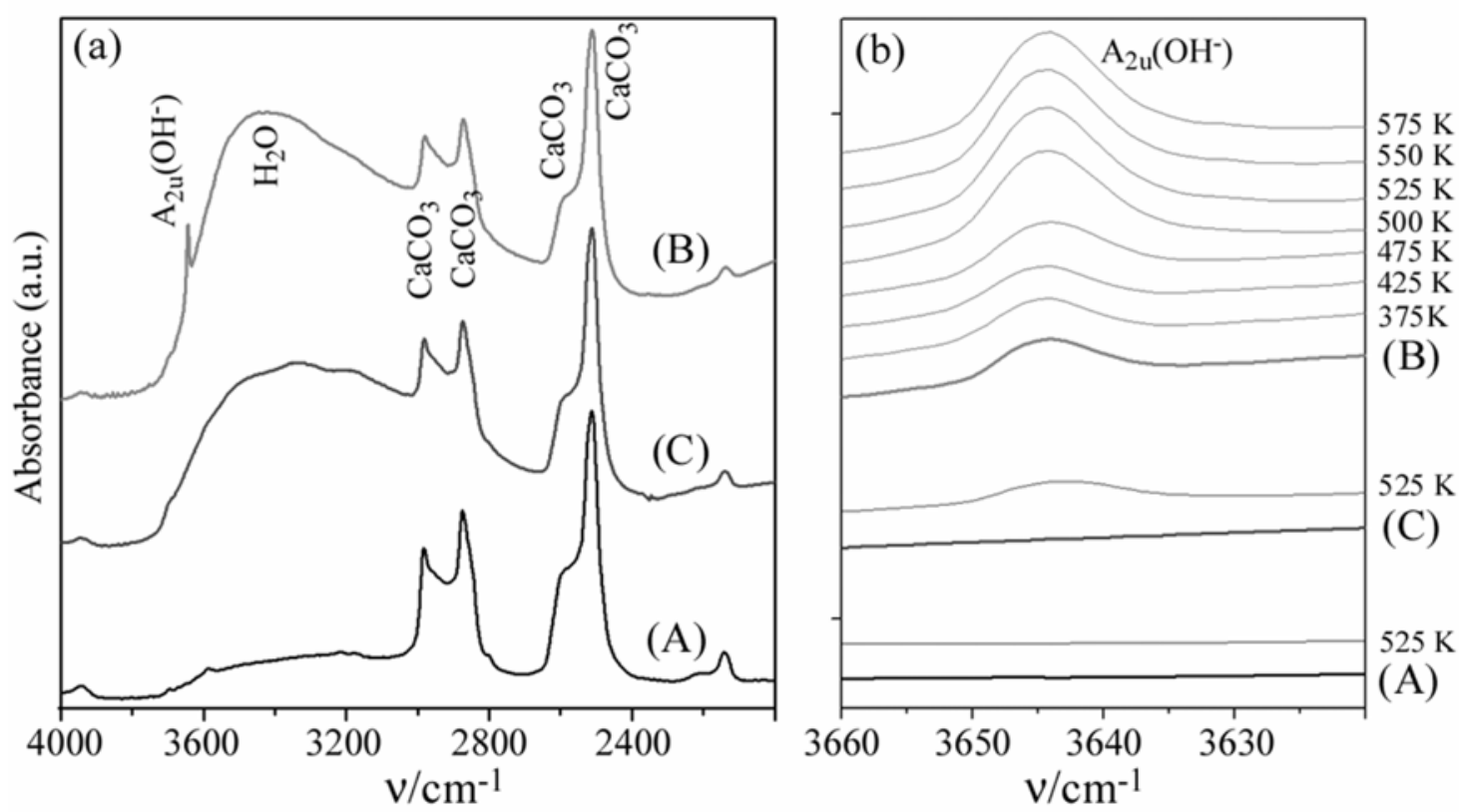
Fig. 6

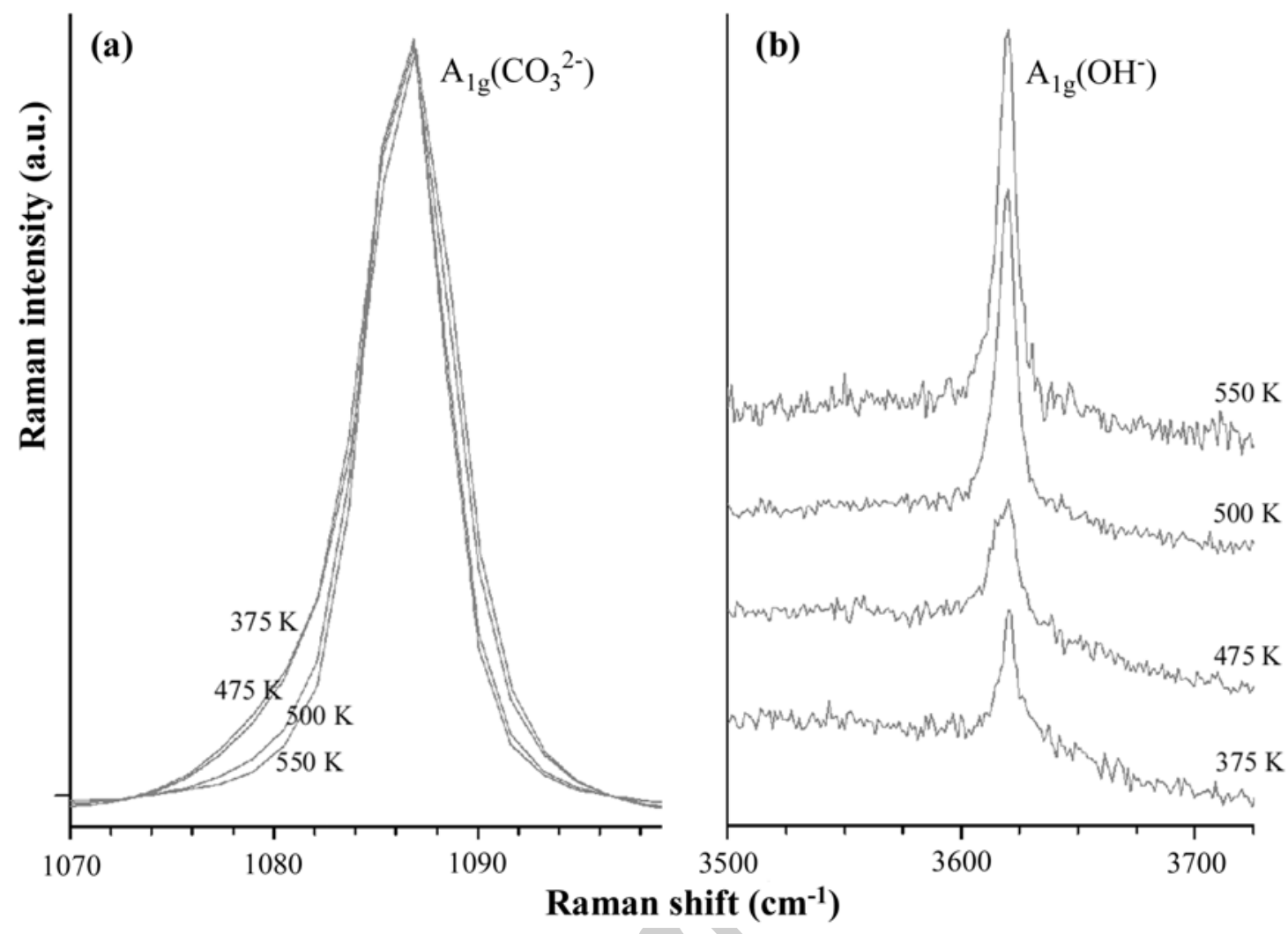


Fig. 7

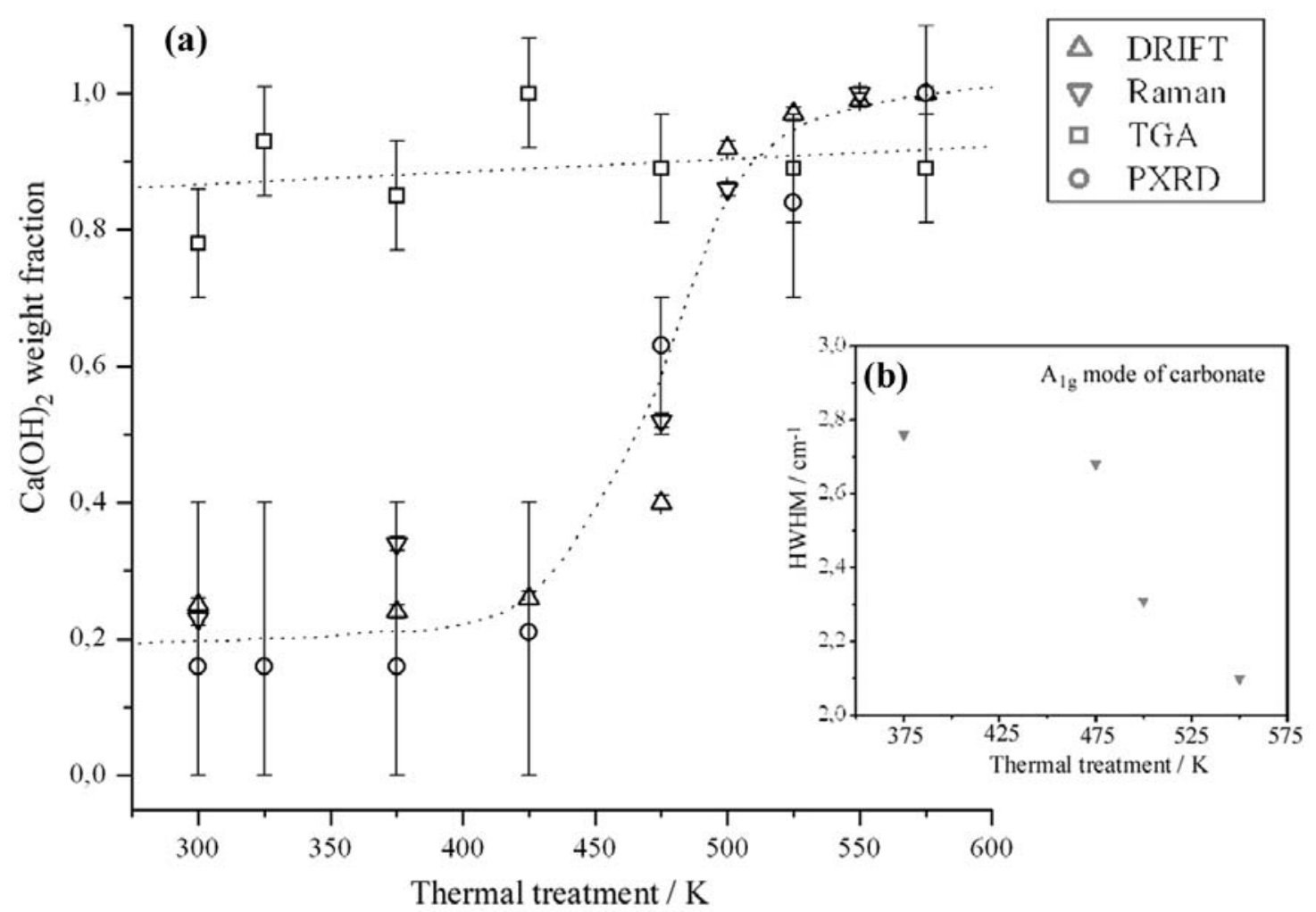


Fig. 8
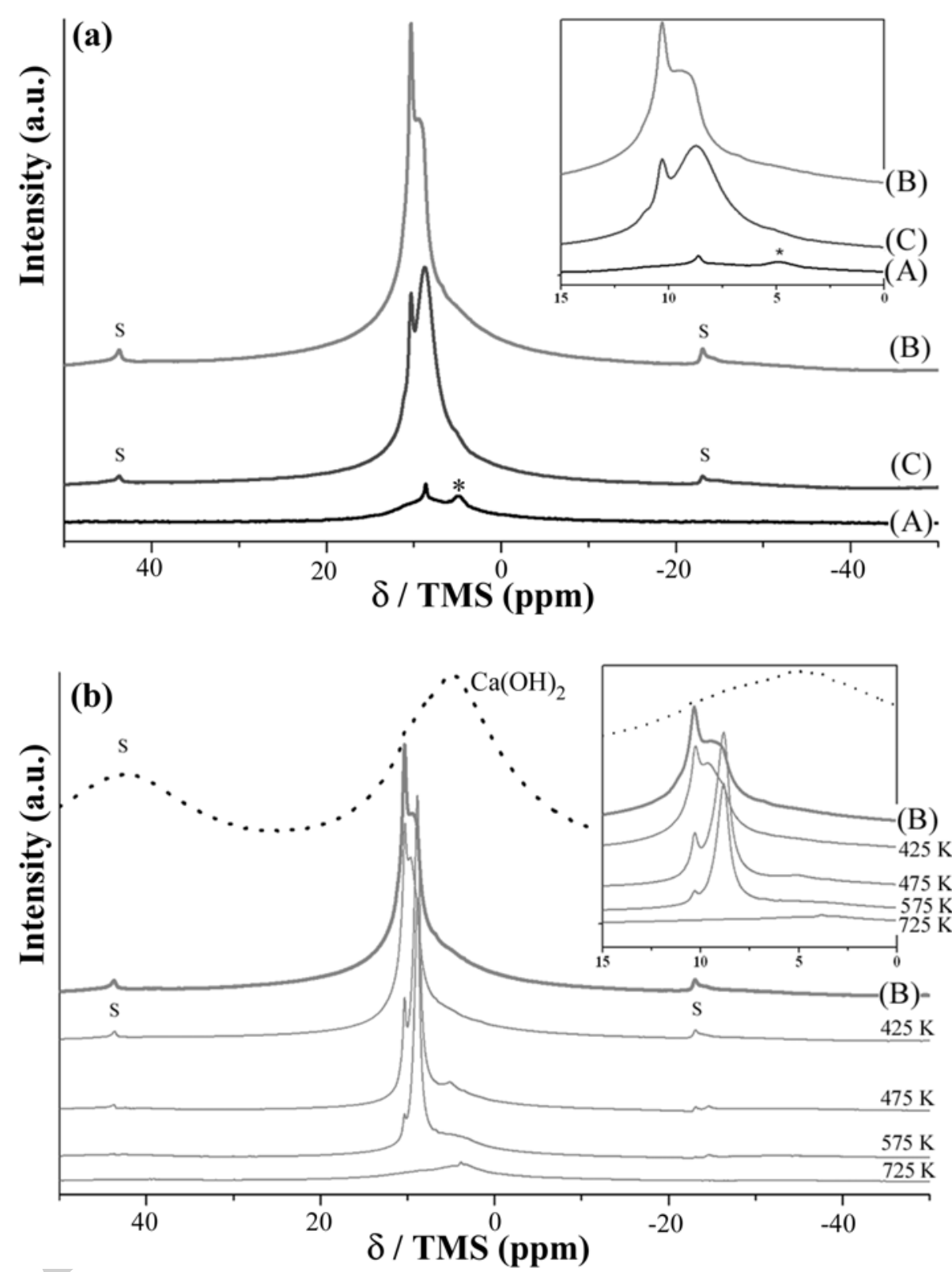